\title{
FLIPPED CLASSROOM: ALTERNATIVE OF THE MODEL OF LEARNING TO IMPROVE STUDENT LEARNING OUTCOMES IN K-10
}

\author{
Maria Paristiowati ${ }^{1}$, Ucu Cahyana ${ }^{2}$, Annisa Nur Fitria ${ }^{3}$. \\ State University of Jakarta \\ maria.paristiowati@unj.ac.id \\ ucucahyana@unj.ac.id \\ annisanurfitria@unj.ac.id
}

\begin{abstract}
This study aimed to determine the effect of applying the flipped classroom model to students' learning outcomes in oxidation-reduction reactions. It was conducted in SMAN 47 Jakarta. Research method is quasi-experimental with nonequivalent control group design. The sample consisted of 72 students were taken with purposive sampling. Independent variables are the flipped classroom model and direct instructional. Chemistry learning outcome became a dependent variable. The flipped classroom model is invers of the traditional learning model. Students learn the instructional material at home through videos and discussions in class. Analysis of the requirement's test showed that the data were normally distributed and had homogeneous variances. Hypothesis testing showed different results in a significant level of 0.05. The differences of average value between pretest and posttest of the experimental group is 12.50. While the differences in the control group was 7.17. It can be concluded that the difference of average value between pretest and posttest of the experimental group is higher than the control group. The flipped classroom model can improve students' learning outcomes in the oxidation-reduction reaction.
\end{abstract}

Keywords: Flipped Classroom, Quasi Experiment, Oxidation-Reduction Reaction, Learning Outcomes

Currently, a wide range of reforms undertaken to improve the quality of education. To improve the quality of education needed a breakthrough both in curriculum development, learning innovation, and fulfillment of educational facilities and infrastructure. To enhance the learning process, the teachers are required to make the learning to be more innovative to encourage students to learn optimally both in self-learning and learning in the classroom.

Traditional learning methods in schools is involving teachers more actively provide information, so that the students were only acting as an agent passive learners. The learning implementation must change, students should be given an active role and be a partner in the learning process so that students become active learner agent. While the teacher becomes a facilitator and creative mediator. It is a 
challenge for a teacher to create a fun learning process and to enhance the activity of students during the learning process.

The flipped classroom is a new learning model that flips the activity inside and outside from the traditional classroom learning. In the flipped classroom learning model, the teacher gives instructional material outside the formal classroom time and using formal classroom time to engage students in solving a problem or assignment through extensive interaction with peers and teachers (Natalie, 2012). The flipped classroom gives opportunity for the teachers to motivate and guide students more specific (Keengwe, 2014). According to Brent (2013) Flipped classroom is a model that can be applied to minimize teacher instruction when teaching while maximizing the interaction between teachers and students. This model utilizes a technology that can provide learning materials for students that can be accessed online. Roehl (2013) said that students spend time in class to problem-solving activities and development of the concept. According to Marlowe (2012), flipped classroom learning model gives a satisfactory student learning outcomes. The study of flipped learning for a pharmaceutics course reported a 5.1\% improvement in student performance (Meyer, 2013). Some educators have reported that implementation of the flipped classroom can improve student attitudes and even better test scores, greater flexibility and lesser stress (Mok, 2014). Overall, students have positive thinking towards learning atmosphere that created by teachers and they can feel the benefits very well.

This study was conducted to determine the effect of applying the flipped classroom learning model on oxidation-reduction reactions material as an alternative model of learning toward students learning outcomes in K-10.

\section{METHOD}

This study uses a quasi-experimental method with nonequivalent control group design. The study was conducted in SMA Negeri 47 Jakarta, with 72 students as sample. In this study, t-tests for two average value of unrelated samples is used to determine differences in the average value of pretest and post-test between the experimental and control groups. In the experimental group, the learning is done with the flipped classroom models. Students learn the material of oxidation-reduction reaction at home through instructional video then guided in a class discussion. Students can learn the instructional video on you tube and they can download it. In the control group, students are taught to conventional models through lectures, discussions, and question and answer.

Indicators which is show the effects of application of the flipped classroom model on the redox reactions material are measured through student learning outcomes. Instruments in this study is pretest and post-test questions, each consisting of 40 questions. Validity and reliability of instrument indicates that the instrument are valid and reliable. 


\section{RESULT AND DISCUSSION}

The data in the experimental group showed the difference highest value is 55 and the lowest value is -30 . The differences of the pretest and posttest in the experimental group which is taught with the model of flipped classroom can be described in figure 1 . The data in the control group showed that difference highest value is 35 and the lowest value is -25 . The differences of the pretest and posttest in the control group which is taught with conventional model can be described in figure 2 .

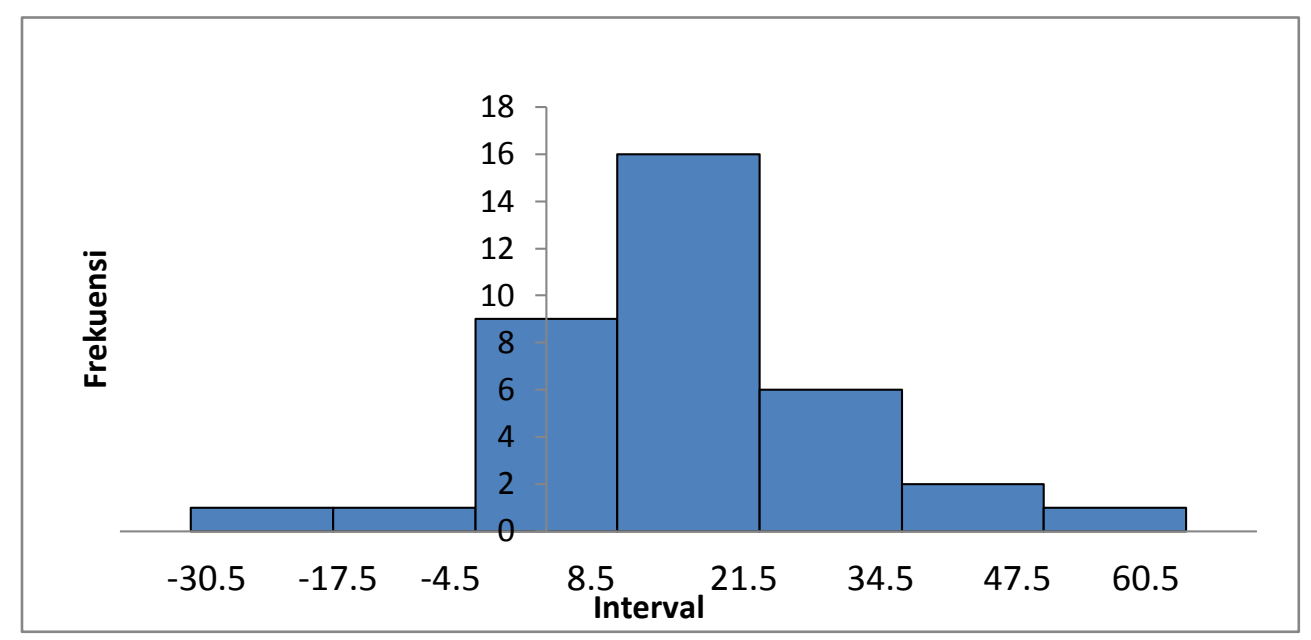

Figure 1. Difference in value of the Experimental Group

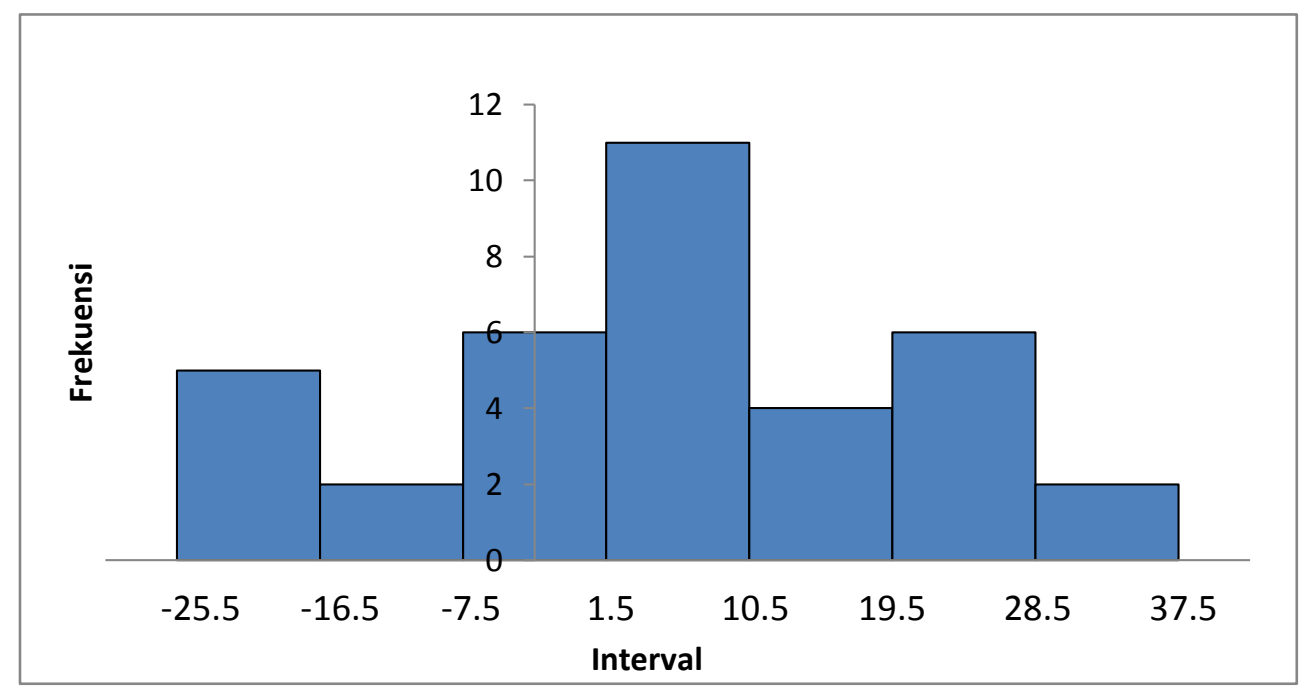

Figure 2. Difference in value of the Control Group 
In the experimental and control groups there is a difference of minus value, because there are students who decreased from pretest to posttest. The overall results can be concluded that the difference in the average value of the pretest and post-test in the experimental group is greater than the control group, ie respectively 12.50 and 7.17. It is illustrated in figure 3.

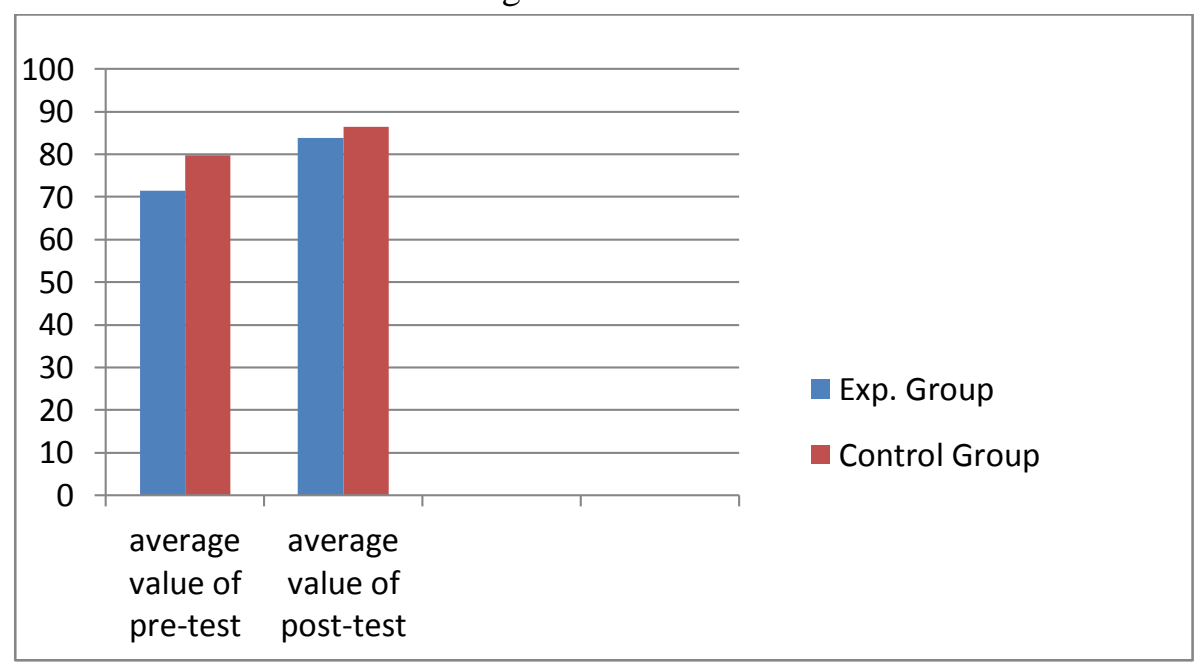

Figure 3. The Difference Value in Experiment Group and Control Group

Normality test for the experimental and control groups show that the data has normal distribution. Based on test of homogeneity indicates that the data has homogeneous variance. Furthermore, based on test of two differences average for unrelated samples with the significance level of 5\% was obtained t-count -2.34 and t-table 1.67. It can be concluded there is a difference between the average value of pretest and posttest in the experimental group and the control group. The difference of average value between pretest and posttest of the experimental group was higher than the control group. So, the result of this study conclude that the application of the flipped classroom model is giving a positive effect on student learning outcomes in redox reaction material.

The flipped classroom model is bringing new atmosphere more fun in chemistry learning in the classroom. It can improve the interaction between teachers and students and among students, so that learning becomes more intensive and better. This learning process is using modern technology that very close to the students' everyday life. The flipped classroom model use the video of learning provided in softcopy and also uploaded to youtube to be more accessible for students. The flipped classroom learning models also enhance the activity and independence of students in learning. Students' understanding of the material to be better because during the learning process going on, the teacher guided the discussions and help solve the problems. 


\section{CONCLUSION}

The difference of average value between pretest and posttest of the experimental group was higher than the control group. Difference in average value between pretest and posttest of the experimental group is higher than the control group. It can be concluded that the application of the flipped classroom model is giving a positive effect on student learning outcomes in redox reaction material.

\section{REFERENCES}

Johnson, Graham Brent. (2013). Student Perceptions of the Flipped Classroom. Columbia: The University Of British Columbia.

Keengwe, Jared. (2014). Promoting Active Learning through the Flipped Classroom Model. USA: IGI Global.

Marlowe, Cara A. (2012). The Effect of The Flipped Classroom on Student Achievement and Stress. Montana: Montana State University

Meyer, R. (2013). "The post-lecture classroom: how will students fare?" The Atlantic.Retrieved from http://www.theatlantic.com/technology/archive/ 2013/09/the-post-lecture-classroom-how-will-students-fare/279663

Milman, Natalie B. (2012). "The Flipped Classroom Strategy: What Is It and How Can It Best Be Used?" Distance Learning, 9 (3), 85-87.

Mok, H. N. (2014). "Teaching tip: The flipped classroom". Journal of Information Systems Education, 25 (1), 7-11.

Roehl, Amy, Shweta Linga R., Gayla Jett S. 2013. "The Flipped Classroom: An Opportunity to Engage Millennial Students through Active Learning Strategies". JFCS, 105 (2), 44-49. 